\title{
Biplot Approach for Identification of Heterotic Crosses in Linseed (Linum usitatissimum L.)
}

\author{
Anu Rastogi, Brij Kishore Mishra, Mrinalini Srivastava, Ameena Siddiqui, and Sudhir Shukla \\ Division of Genetics and Plant Breeding, National Botanical Research Institute, Lucknow 226001, India \\ Correspondence should be addressed to Sudhir Shukla, s_shukla31@rediffmail.com \\ Received 19 July 2011; Revised 9 September 2011; Accepted 15 September 2011 \\ Academic Editor: Zed Rengel \\ Copyright () 2011 Anu Rastogi et al. This is an open access article distributed under the Creative Commons Attribution License, \\ which permits unrestricted use, distribution, and reproduction in any medium, provided the original work is properly cited.
}

In India, among nonedible oilseed crops, linseed is a commercial crop having tremendous economic and industrial importance. The seed production is low due to limited resources, so the development of high-yielding lines with desirable characters is urgently needed. In the present study seven parents' half diallel data was subjected to biplot analysis to identify the heterotic crosses, genetically similar parents, and to study their interrelationship. Parent Sln-Ys with A-79 and A-03 with A-79 for capsules per plant and seed yield, parent Mukta with Sln-Ys and Mukta with BAU-45 for seeds per capsule, and parents Mukta, A-103, A-79 and A-94 for test weight had lowest correlation. Parent B [Mukta] and F [A-79] were good general combiner for all the traits. The crosses F [A-79] $\times$ A [Sln-Ys] and D [A-03] $\times$ F [A-79] for capsules per plant, test weight and seed yield per plant, cross D $[\mathrm{A}-03] \times \mathrm{A}$ [Sln-Ys] for capsules per plant and test weight and cross D [A-03] $\times$ F [A-79] for test weight and seed yield per plant were heterotic. None of the crosses were heterotic for seeds per capsule.

\section{Introduction}

In terms of production and value, oilseed crops are second major agriculture crops next to food grains in India. Linseed (Linum usitatissimum L.) is an oldest domesticated and economically important industrial nonedible oilseed crop which is being cultivated for seed and its fiber since centuries [1]. The whole plant has commercial use directly or indirectly and also has capability to substantiate the existing natural demand of oil. The crop is generally cultivated under marginal and rain-fed conditions [2]. The area under cultivation is approximately. 1.9 million hectares in India. The average seed yield of linseed in India is $403 \mathrm{Kg} / \mathrm{ha}$ which is comparably very low in comparison with world average seed yield that is $943 \mathrm{Kg} / \mathrm{ha}$ [3-5]. The low seed yield is chiefly due to limited resources available to poor farmers along with nonavailability of high-yielding cultivars [6]. So, the development of high-yielding varieties/lines is needed to compete with other linseed growing countries. Such lines/varieties can easily be developed through suitable hybridization and selection programmes to isolate superior segregants [7]. However, the success of any hybridization programme chiefly depends on combining ability of parents used in crossing programme [8]. Combining ability provides an important tool for selection of desirable parents and to get required information regarding the nature of gene action controlling desirable trait [9]. Generally, plant breeders use Griffing's [10] diallel mating design to identify desirable parents along with their specific cross-combinations and to get the knowledge of genetic effects, estimates of general combining ability (GCA), specific combining ability (SCA) and variance components [11-15]. It also provides information about inheritance of important traits, identification of promising heterotic combinations, and heterotic patterns based on partitioning of total variance into GCA and SCA [16]. In diallel analysis GCA is associated with the parents and SCA with the hybrids. Yan and Hunt [17] developed a new GGE biplot model for analyzing the diallel data to obtain combining ability and interrelationships of parents based on graphical presentation using PC1 and PC2 which are derived through PC analysis of environment-centered yield data. The present study was undertaken for the first time to analyze diallel data using GGE biplot model to gather information about genetic interrelationships among parents and identification of heterotic combinations for high seed yield in linseed. 


\section{Materials and Methods}

The material for the present study comprised of seven pure and homozygous lines namely, a yellow-seeded selection Sln-Ys (Parent A) and six other high-yielding varieties, namely, Mukta (Parent B), A-103 (Parent C), A-03 (Parent D), BAU-45 (Parent E), A-79 (Parent F), and A-94 (Parent G) of linseed (Linum usitatissimum L.) which were crossed in diallel fashion excluding reciprocals to get $F_{1}$ seeds in year 2005-2006. The $F_{1} s$ were grown in randomized block design with three replications in year 2006-2007 at the experimental field of Genetics and Plant Breeding, NBRI, Lucknow which is situated at $26^{\circ} \mathrm{N}, 80.5^{\circ} \mathrm{E}$, and $120 \mathrm{~m}$ above sea level. Each parent (entry/tester) and their hybrids were sown in two rows with row-to-row and plant-to-plant spacing of $30 \times 20 \mathrm{~cm}^{2}$. The length of each row was 3 meters. During experimentation, normal cultural practices were applied. The data on morphological traits and seed yield $(\mathrm{gm})$ were recorded on 10 competitive plants from each entry/replication. The mean data was subjected to graphical analysis using Yan's GGE biplot software. In GGE biplot, mean and stability of genotypes referred to GCA and SCA of parents, respectively [17]. The results obtained from GGE biplot analysis are displayed in two ways (i) graphical view having concentric rings with vectors of entries which provides information about interrelationships among parents in producing heterotic crosses and (ii) ATC polygon view to study GCA, SCA, and heterotic combinations.

The analysis of interrelationship between parents/entries/testers can be approximated by cosine of the angle between parents:

$$
\cos [a i j]=r i j,
$$

where $a i j$ is the angle between parent $i$ and parent $j$ and $r i j$ is the correlation coefficient between both parents.

Two parents are positively correlated if the angle between their vectors is $<90^{\circ}$, are negatively correlated if the angle is $>90^{\circ}$, and independent if the angle between them is $90^{\circ} .0^{\circ}$ means correlation $[r]$ is 1 and $180^{\circ}$ means correlation is -1 . Testers with longer vectors are more discriminating of the entries, those with short vectors are less discriminating and those located at the biplot origin are not discriminating.

In the ATC polygon view, results were shown according to the average tester position which is a virtual tester (i.e., PC1 and PC2 scores = average PC1 and PC2 scores) across all the testers. The ATC was established with its abscissa by passing through the origin. GCA effects of the entries are approximated by their projections onto the ATC abscissa. Parallel lines perpendicular to the abscissa help in ranking of entries in terms of GCA. The projections of the entries onto ATC coordinate displayed SCA effects which represent the tendency of the entries to produce superior hybrids. The polygon view of the biplot is drawn by connecting the entries. The perpendicular line to each side drawn from the origin of the plot divides the biplot into several sectors, and each tester falls into one sector. Tester falling in a sector shares the best mating partner with another entry present at the vertex of the polygon in that sector. Entries located near the biplot origin are less responsive to the change of the testers.
As a rule in biplot analysis for the diallel data, each genotype was considered both as an entry (with normal letters) and a tester (with bold and capital letters).

To check the authenticity of GGE biplot in displaying the heterotic crosses, heterosis over mid- and better parents were also calculated using the following formula:

$$
\begin{aligned}
& \text { Heterosis at } \mathrm{MP}[\%]=F_{1}-\frac{\mathrm{MP}}{\mathrm{MP} \times 100}, \\
& \text { Heterosis at } \mathrm{BP}[\%]=F_{1}-\frac{\mathrm{BP}}{\mathrm{BP} \times 100} .
\end{aligned}
$$

\section{Results}

The analysis of variance showed significant differences among parents for all the traits except seeds per capsule (Table 1). The $F_{1}$ s, parents, and parents versus hybrids were also significant for all the traits except seeds per capsule. Hybrids had greater mean sum of square (MSS) than parents for all the traits which suggested that significant heterosis existed in the hybrids (Table 2).

3.1. Capsules per Plant. Graphical representation of concentric rings with vectors showed interrelationships among testers or entries. Parent A showed largest variation, while parent $\mathrm{D}$ had lowest variation (Figure $1(\mathrm{a})$ ). The vector of parent B with $\mathrm{C}$, A with $\mathrm{G}, \mathrm{C}$ with $\mathrm{A}, \mathrm{A}$ with $\mathrm{D}$, D with $G$, and $G$ with $F$ had acute angles which suggested positive correlation among them, while parents $\mathrm{A}$ with $\mathrm{F}$ and $\mathrm{D}$ with $\mathrm{F}$ had obtuse angles which suggested lowest correlation among them and should produce heterotic crosses (Figure 1(a)).

The principal components together explained 33.7\% (20.6\% and $13.1 \%$ by $\mathrm{PC} 1$ and PC2, resp.) of the total variation (Figure 1(b)). The remaining proportion of the total variation was not accounted by biplot analysis due to much complexity in genetics involved in this trait among the seven parents. The parents F, B, E, and C had positive GCA, whereas G, A, and D had negative GCA effects. Based on the distance between entry and ATC abscissa, entry F had greatest GCA followed by parents $\mathrm{B}, \mathrm{C}, \mathrm{D}=\mathrm{G}, \mathrm{A}$ and E. Parents A and F had highest SCA based on the largest projections onto the abscissa. The group of parents $\mathrm{D}, \mathrm{B}$ and $\mathrm{G}$ and $\mathrm{C}$ and $\mathrm{E}$ were similar with each other due to their close presence in the polygon. The biplot clearly viewed three welldefined sectors, that is, A, F, and B. The two heterotic groups $[F, G, D]$ and $[B, C, A]$ were observed which suggested that the hybrids between these groups should show heterosis that can also be verified through polygon data. Entry BAU-45 was located near to abscissa and did not seem to belong to any group. The crosses $\mathrm{F} \times \mathrm{A}$ and $\mathrm{F} \times \mathrm{D}$ in sector $\mathrm{F}$ and crosses $\mathrm{A} \times \mathrm{F}$ and $\mathrm{A} \times \mathrm{D}$ in sector $\mathrm{A}$ would be heterotic due to the presence of parents as testers in their respective sectors.

3.2. Seeds Per Capsule. Graphical representation of concentric rings with vectors revealed that parent $\mathrm{A}$ with $\mathrm{E}$ had largest variation due to largest vectors and obtuse angle. Similarily parents B with A and B with $\mathrm{E}$ also had ob-tuse angle, so should be expected to produce heterotic combinations 


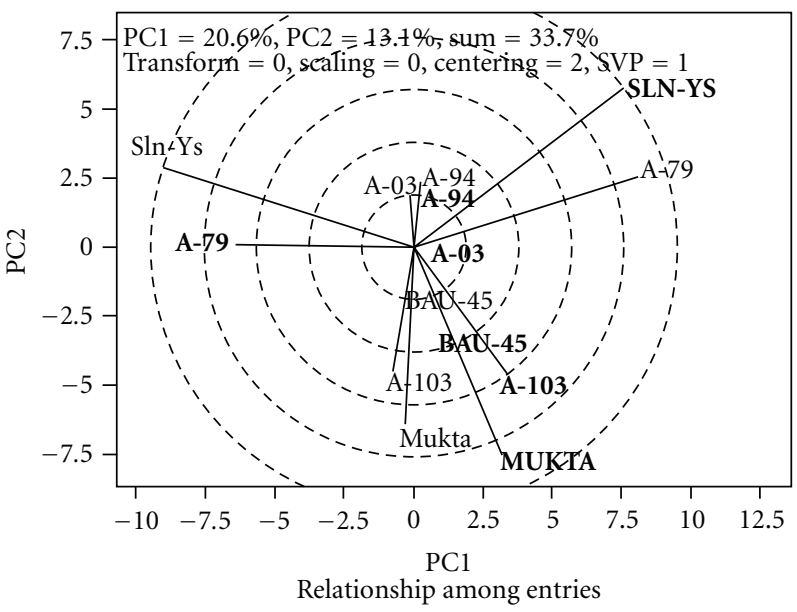

(a)

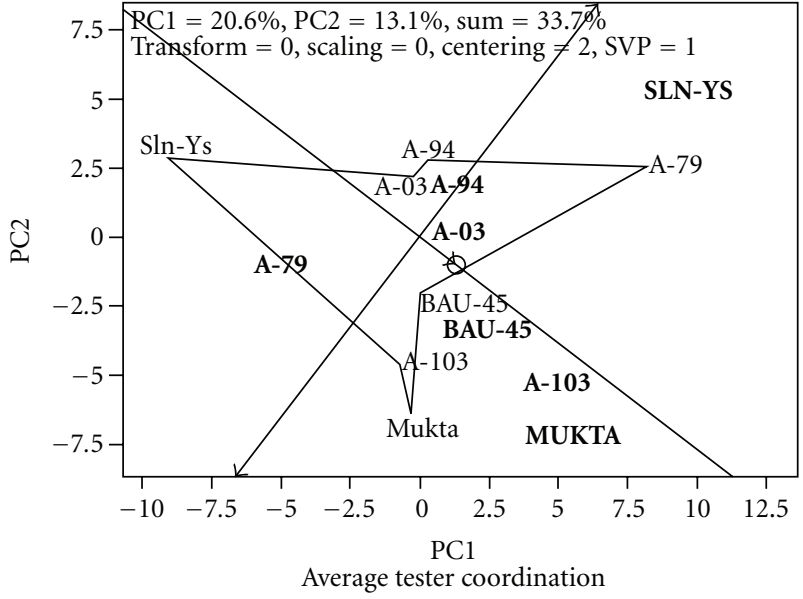

(b)

FIGURE 1: (a) Interrelationships among testers (bold capital letters) and entries (normal letters) and (b) polygon view for capsules/plant.

TABLE 1: Analysis of variance for different traits in linseed.

\begin{tabular}{lccccc}
\hline Source & df & Capsules/plant & Seeds/capsule & Test weight & Seed yield \\
\hline Treatment & 27 & $3044.95^{* *}$ & 70.96 & $4.31^{* *}$ & 1.49 \\
Replication & 2 & 3673.36 & 70.86 & $9.89^{* *}$ & 1.95 \\
Parents & 6 & $4411.57^{* *}$ & 0.52 & $9.54^{* *}$ & $39.22^{* *}$ \\
$F_{1}$ & 20 & $2462.77^{* *}$ & 95.42 & $2.81^{* *}$ & $9.98^{* *}$ \\
Parents versus $F_{1}$ & 1 & $6488.79^{*}$ & 4.59 & $2.83^{*}$ & 0.54 \\
Error & 54 & 1050.11 & 72.45 & $2.04^{* *}$ \\
\hline
\end{tabular}

$* P<0.05$ and $* * P<0.01$.

which can be verified through polygon view. Parents B, G, C, $\mathrm{D}$, and $\mathrm{F}$ were found highly correlated as they had acute angle and small vectors among them, so were unable to produce heterotic combinations (Figure 2(a)).

First two principal components explained 95.7\% [PC1 = $53.2 \%$ and $\mathrm{PC} 2=42.5 \%$ ] of total variation (Figure $2(\mathrm{~b})$ ). The remaining less proportion of the total variation was not accounted by the biplot due to complexity in genetics involved for this trait among the seven parents. Based on the ATC, parent $\mathrm{E}$ had highest GCA followed by $\mathrm{A}>\mathrm{G}>\mathrm{B}>\mathrm{F}$ $>\mathrm{C}>\mathrm{D}$. Parents $\mathrm{E}$ and A had highest SCA effects based on their largest projections onto the ATC. Entries B, C, E, F, and $\mathrm{G}$ showed similarity among them due to their close presence in polygon. Two heterotic groups $[\mathrm{A}, \mathrm{C}]$ and $[\mathrm{E}, \mathrm{D}, \mathrm{F}, \mathrm{B}$, $G$ ] were observed which suggested that ten hybrids between $[A, C] \times[E, D, F, B, G]$ should show heterosis that can also be verified through polygon view. Three sectors that is, E, A, and $\mathrm{D}$, were clearly viewed. The crosses $\mathrm{E} \times \mathrm{A}, \mathrm{E} \times \mathrm{G}$ and $\mathrm{E} \times \mathrm{B}$ were heterotic in sector $\mathrm{E}$ due to presence of parents $A, G$, and $B$ as testers in sector $E$ and cross $A \times E$ in sector $A$ due to presence of parent $\mathrm{E}$ as tester.

3.3. Test Weight. The graphical representation of concentric rings with vectors showing interrelationships among the testers or entries [both showed same results] showed that the parents $\mathrm{B}, \mathrm{C}, \mathrm{F}$, and $\mathrm{G}$ had largest vectors and obtuse angle among themselves which suggested existence of largest variation and less correlation. So, the crosses produce by using these parents would be expected heterotic crosses that can be verified through polygon view. Parent $A$ with $\mathrm{E}$ and $\mathrm{E}$ with $C$ had acute angle and small vectors so these were highly correlated and cannot be able to produce heterotic crosses (Figure 3(a)).

The first two principal components explained $74.3 \%$ [PC1 38.2\% and PC2 36.1\%] of the total variation (Figure $3(\mathrm{~b})$ ). The remaining proportion of total variation was not accounted by biplot, reflecting the complexity of genetics involved among the seven parents for this trait. Based on the projection onto ATC abscissa, parents B, D, $\mathrm{C}$, and $\mathrm{E}$ had positive GCA. Parent B with parent D had highest GCA effect followed by the parents $F>G>E>$ A. The parents D and B had highest SCA effect. The two heterotic groups $[A, F] \times[D, C, E, A, G]$ were observed that were expected to show heterotic combinations. The heterotic crosses were $\mathrm{F} \times \mathrm{E}$ and $\mathrm{F} \times \mathrm{A}$ [as $\mathrm{A}$ was present on the perpendicular fall] in sector $\mathrm{F}$. The cross $\mathrm{D} \times \mathrm{F}$ was heterotic as $\mathrm{F}$ was present as tester in sector $\mathrm{F}$, and cross $\mathrm{D} \times \mathrm{A}$ was heterotic as A was present as another genotype in sector D. Parent $\mathrm{B}$ was present perpendicular to sector $\mathrm{B}$ and $\mathrm{D}$, thus would be equal mating partners in both sectors, but sector $\mathrm{B}$ had same parent $B$ as tester, so only the cross $B \times D$ would be heterotic combination in sector $\mathrm{B}$. 
TABLE 2: Estimate of heterosis over mid- and better parent for different traits in linseed.

\begin{tabular}{|c|c|c|c|c|c|c|c|c|}
\hline \multirow[t]{2}{*}{ Crosses } & \multicolumn{2}{|c|}{ Capsule/plant } & \multicolumn{2}{|c|}{ Seeds/capsule } & \multicolumn{2}{|c|}{ Test weight } & \multicolumn{2}{|c|}{ Seed yield } \\
\hline & MP & $\mathrm{BP}$ & MP & $\mathrm{BP}$ & MP & $\mathrm{BP}$ & MP & $\mathrm{BP}$ \\
\hline Sln-Ys $\times$ Mukta & -45.39 & $-64.83^{* *}$ & 0.00 & -6.25 & -23.00 & $-53.33^{* *}$ & $-73.42^{* *}$ & $-83.96^{* *}$ \\
\hline Sln-Ys $\times$ A-103 & -4.66 & -36.44 & -46.38 & -47.50 & $59.67^{*}$ & 8.00 & $-51.67^{*}$ & $-69.02^{* *}$ \\
\hline Sln-Ys $\times$ A-03 & $210.74^{* *}$ & $209.73^{* *}$ & -26.67 & -31.25 & $223.26^{* *}$ & $122.13^{*}$ & 102.72 & 67.75 \\
\hline Sln-Ys $\times$ BAU -45 & 25.99 & -15.73 & $299.17^{* *}$ & $299.17^{* *}$ & $88.70^{* *}$ & 27.77 & 9.53 & -26.34 \\
\hline Sln-Ys $\times$ A-79 & $281.57^{* *}$ & $217.97^{* *}$ & -29.46 & -31.67 & $366.75^{* *}$ & $218.87^{* *}$ & $229.14^{* *}$ & $178.83^{* *}$ \\
\hline Sln-Ys $\times$ A-94 & 39.43 & -10.09 & 4.58 & 4.58 & 30.54 & -18.73 & -0.71 & $-39.70^{*}$ \\
\hline Mukta $\times$ A-103 & $46.67^{*}$ & 36.72 & -3.18 & -7.39 & -12.61 & $-31.53^{*}$ & -16.86 & $-28.93^{*}$ \\
\hline Mukta $\times$ A-03 & 18.25 & -23.73 & -49.05 & -49.05 & $81.83^{* *}$ & -2.28 & 11.82 & $-36.77^{*}$ \\
\hline Mukta $\times$ BAU-45 & 17.53 & 8.90 & 0.00 & -6.25 & -12.38 & $-31.4^{*}$ & -15.30 & $-33.10^{* *}$ \\
\hline Mukta $\times$ A-79 & 19.13 & -14.69 & 10.34 & 6.67 & $-79.81^{* *}$ & $-89.17^{*}$ & $-55.80^{* *}$ & $-74.83^{* *}$ \\
\hline Mukta $\times$ A-94 & -34.84 & -35.03 & 11.11 & 4.17 & $-85.09^{* *}$ & $-86.47^{* *}$ & $-77.29^{* *}$ & $-78.07^{* *}$ \\
\hline A-103 $\times$ A-03 & 25.53 & -16.18 & -12.44 & -17.92 & 5.11 & $-40.89^{*}$ & $-55.51^{*}$ & $-73.59^{* *}$ \\
\hline A-103 $\times$ BAU -45 & -6.91 & -7.52 & 1.67 & 1.67 & -20.46 & -22.81 & $-34.88^{*}$ & $-40.48^{*}$ \\
\hline A-103 $\times$ A-79 & 58.17 & 18.63 & -12.69 & -15.42 & $66.06^{*}$ & -6.83 & -13.30 & $-48.05^{* *}$ \\
\hline A- $103 \times$ A-94 & 0.30 & -6.25 & -13.33 & -13.33 & $-39.63^{* *}$ & $-47.61^{* *}$ & $-32.28^{*}$ & $-40.70^{* *}$ \\
\hline A- $-03 \times$ BAU -45 & 18.32 & -20.86 & -18.67 & -23.75 & 71.45 & -14.28 & -31.96 & $-60.11^{* *}$ \\
\hline A- $-03 \times$ A-79 & $157.25^{* *}$ & $114.38^{*}$ & -0.23 & -3.56 & $1469.79^{* *}$ & $684.90^{* *}$ & $450.10^{* *}$ & $373.12^{* *}$ \\
\hline A- $-03 \times$ A- 94 & 3.74 & -33.10 & -23.11 & -27.92 & 41.90 & -29.05 & $-53.02^{*}$ & $-73.99^{* *}$ \\
\hline BAU-45 $\times$ A-79 & 45.39 & 9.41 & 6.67 & 3.33 & $95.11^{* *}$ & 9.47 & 57.45 & -3.06 \\
\hline BAU-45 × A-94 & -28.09 & -33.10 & 12.50 & 12.50 & -8.78 & -20.84 & $-43.93^{* *}$ & $-53.92^{* *}$ \\
\hline A-79 $\times$ A-94 & 28.12 & -8.10 & -5.00 & -5.00 & 34.87 & $-32.56^{*}$ & $-48.64^{*}$ & $-71.57^{* *}$ \\
\hline S.E. & 22.91 & 26.46 & 6.02 & 6.95 & 0.52 & 0.60 & 1.06 & 1.22 \\
\hline $\mathrm{CD}$ at $5 \%$ & 45.94 & 53.05 & 12.07 & 13.93 & 1.05 & 1.21 & 2.12 & 2.46 \\
\hline $\mathrm{CD}$ at $1 \%$ & 61.18 & 70.64 & 16.07 & 18.56 & 1.39 & 1.61 & 2.83 & 3.27 \\
\hline
\end{tabular}

$* P<0.05$ and ${ }^{* *} P<0.01$.

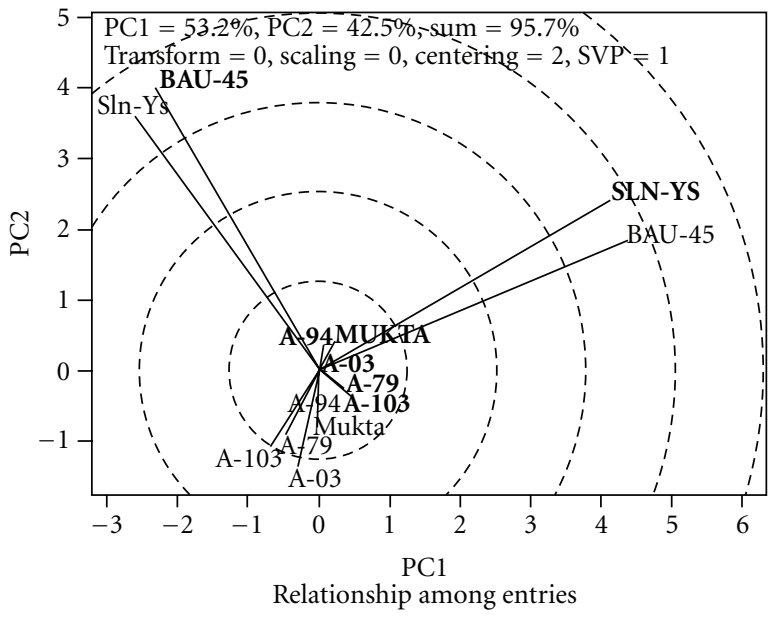

(a)

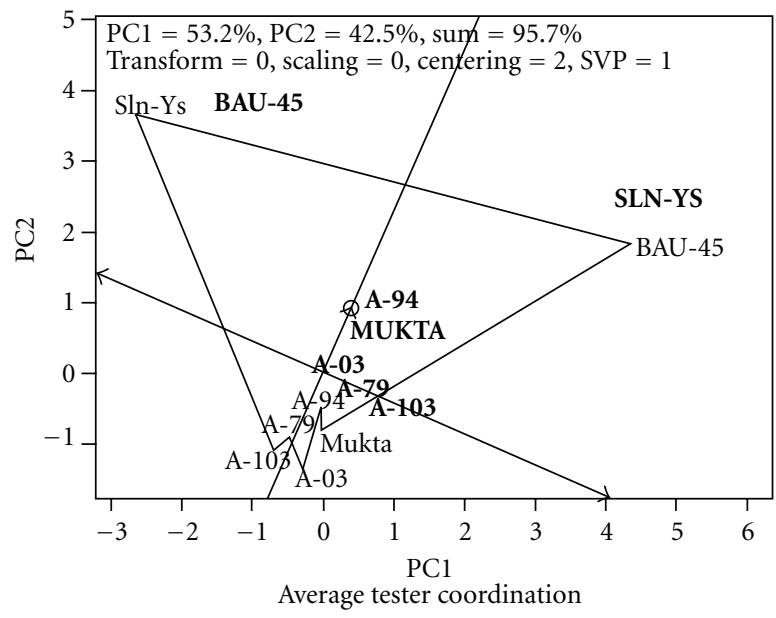

(b)

Figure 2: (a) Interrelationships among testers (bold capital letters) and entries (normal letters) and (b) polygon view for seeds/capsule.

3.4. Seed Yield. The graphical representation of concentric rings with vectors showed interrelationships among testers/ entries (both showed same results). Parent F with D, F with E, F with C, B with D, and B with $G$ had largest variation and obtuse angle showing smallest correlation, while parents E,
C, D, A, and G had smallest vectors and acute angle which showed largest correlation among them (Figure 4(a)). Parent B had obtuse angle with parents F, G, and A but unable to produce heterotic combination due to their presence near to the vector. The parent A was present on the same concentric 


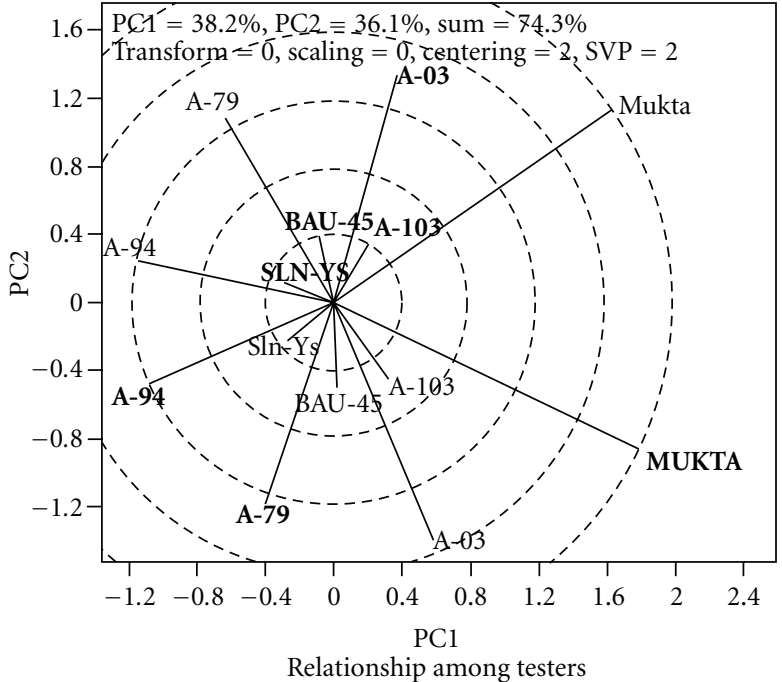

(a)

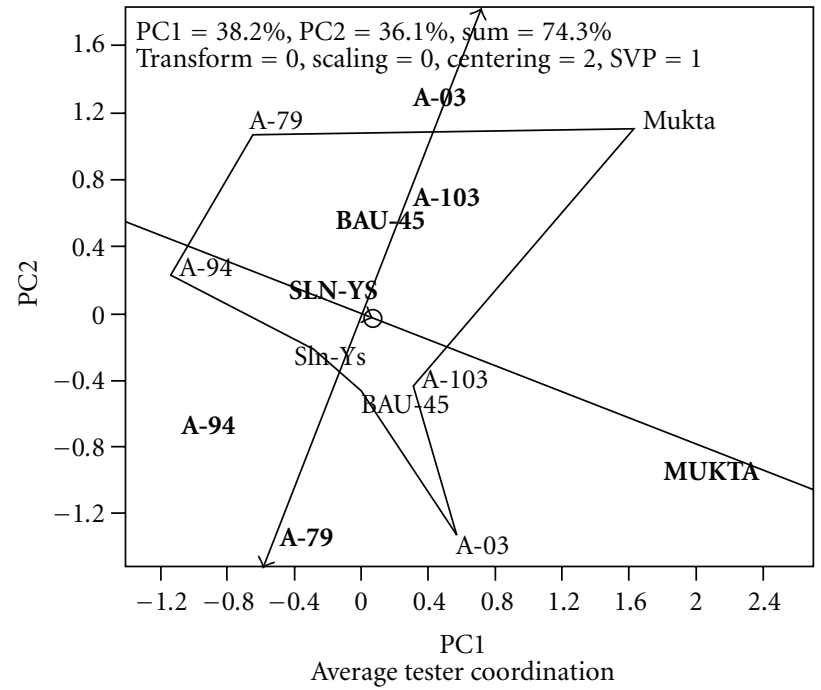

(b)

FIGURE 3: (a) Interrelationships among testers (bold capital letters) and entries (normal letters) and (b) polygon view test weight.

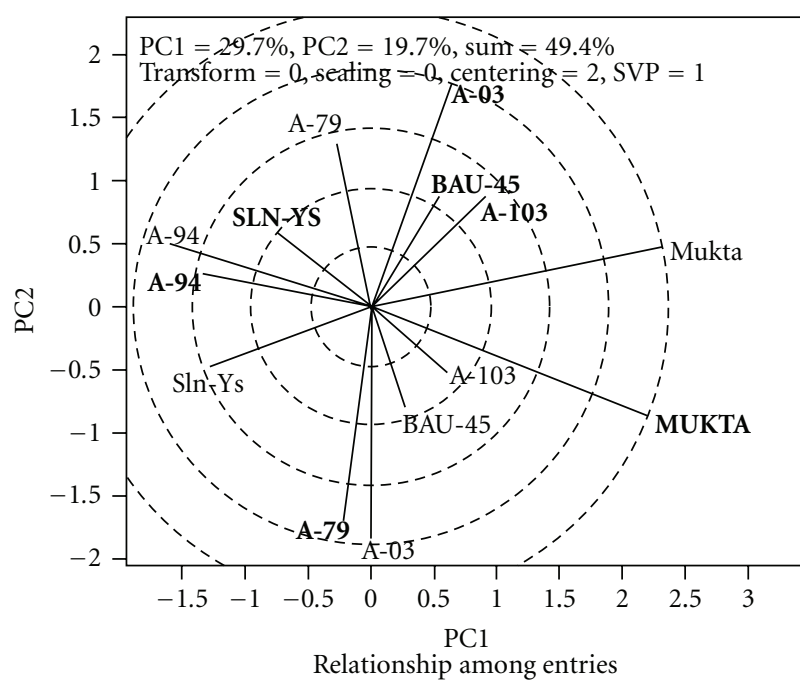

(a)

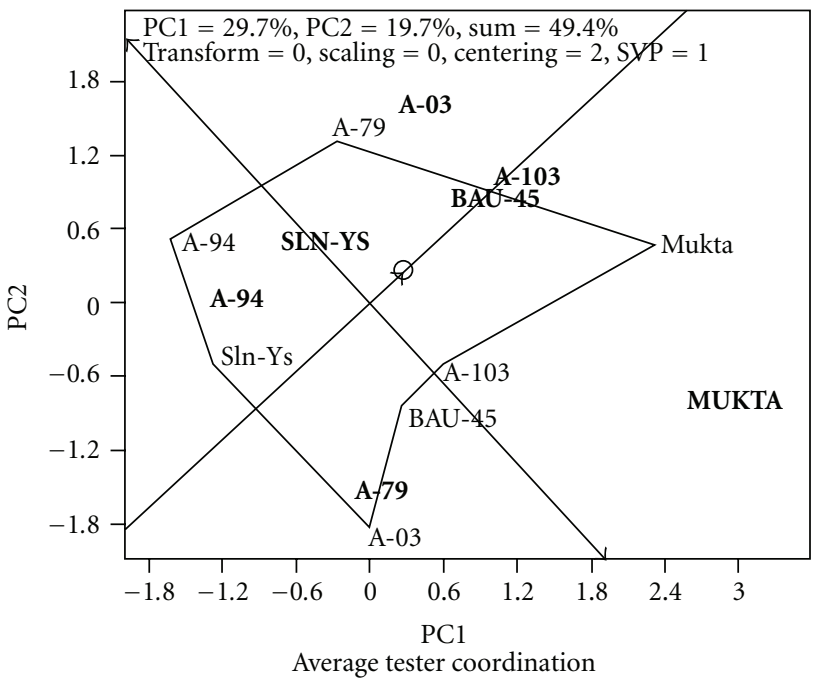

(b)

FIGURE 4: (a) Interrelationships among testers (bold capital letters) and entries (normal letters) and (b) polygon view for seed yield.

circle near to vector $\mathrm{F}$; therefore, cross $\mathrm{A} \times \mathrm{F}$ would be heterotic combination. Similarly, vector F was near to parent $\mathrm{D}$ thus $\mathrm{F} \times \mathrm{D}$ would be heterotic which can also be confirmed through the polygon view.

The principal components together explained only $49.4 \%$ (29.7\% and $19.7 \%$ by PC1 and PC2, resp.) of total variation (Figure $4(\mathrm{~b})$ ). The remaining proportion of total variation was not accounted by biplot due to much complexity in genetics involved among all parents for this trait. The ATC view showed that parents B, F, and C had positive GCA. Based on the projection onto ATC abscissa, parent $\mathrm{B}$ had highest GCA followed by the parents $\mathrm{F}>\mathrm{C}>\mathrm{E}$ $>\mathrm{G}>\mathrm{A}=\mathrm{D}$ and parents $\mathrm{F}$ and $\mathrm{B}$ had highest SCA. Entries $D$ and $G$ were seen similar due to their nearby presence in polygon. The polygon view clearly showed four sectors, that is, $B, F, G$, and D. The two heterotic groups $[F, G, A] \times$ $[B, C, E, D]$ were observed which should show heterotic combinations. Heterotic crosses were $\mathrm{D} \times \mathrm{F}, \mathrm{E} \times \mathrm{F}$, and $\mathrm{F} \times \mathrm{A}$ due to presence of parent $\mathrm{A}$ as tester in sector $\mathrm{F}$.

\section{Discussion}

In recent days, enhancement in yield potential of linseed is a major focused area. To achieve the desired enhancement in yield, genetical improvement of the crop is utmost important. For genetical improvement in any crop, various breeding techniques are used among which diallel is most common one. Improvement in any crop can easily be 
achieved by using good combiners in hybridization programme followed by successive cycle of selection. So, diallel selective mating design suggested by Jensen [18] would be an ideal approach to meet out desired genetic improvement. Griffing [10] model for analyzing diallel data is an old and less interpretative method, while Yan's GGE biplot method enhances the capability of interpretation of diallel data and tries to interpret the phenotypic variation [17]. It is also preferred over conventional diallel approach because it gives jointly GCA and SCA effects of the population and the performances of the crosses as well as grouping pattern of similar genotypes [16].

The analysis of variance showed wide spread significant differences among the parents, and $F_{1}$ s suggested a great amount of genetic variability existed among the parents for all the traits except seeds per capsule. Less difference among the treatments for seeds per capsule was due to variation in number of seeds from seven to eleven. In the present study, parents $\mathrm{B}$ and $\mathrm{F}$ were good general combiners for all the traits. However, other parents were not good combiners for more than two traits. Parent F had highest SCA for capsules per plant and seed yield, parent B for test weight and seed yield, and parent A for capsules per plant and seeds per capsule. In Griffing's diallel approach, all variations are accounted through GCA and SCA in which parents are evaluated only on their GCA effects and the term SCA is associated with the crosses that has little impact in understanding the parents. In biplot analysis, SCA effects are associated with the parents rather than hybrids [17]. The crosses $\mathrm{F} \times \mathrm{A}$ and $\mathrm{D} \times \mathrm{F}$ were heterotic for capsules per plant, test weight, and seed yield per plant, cross $\mathrm{D} \times \mathrm{A}$ for capsules per plant and test weight and cross $\mathrm{E} \times \mathrm{F}$ for test weight and seed yield per plant were found heterotic. It is pertinent to say that the hybrids, which were much superior over their parents, might be due to that the parents involved in the crosses were genetically different [8]. All crosses showed involvement of both high $\times$ high and high $\times$ low general combiners. The crosses involving high $\times$ low general combiners besides expressing favorable additive effects of high parent showed complementary gene action due to interaction between favorable genes contributed by the relevant parents [19]. No crosses showed heterotic response for the trait seeds per capsule. Mahto and Rahman [20] also noticed least heterotic effects for seeds per capsule. The parents involved in heterotic crosses, if belong to the same heterotic groups as in case of cross $\mathrm{F} \times \mathrm{A}$ for seed yield and test weight, the heterotic effect might be due to overdominance or epistatic effect of different dominant genes present in parents F and A [21, 22]. Simultaneously, the parents of heterotic crosses, if belong to different groups, showed heterosis due to dominant gene effects. Similarly, if similar parents show heterotic responses, it might be due to same dominant genes present within them as in the case of cross $\mathrm{E} \times \mathrm{G}$ for seeds per capsule. Other workers also reported the role of different gene effects in the inheritance of respective traits [2, 23-26]. It is interesting to note that all the heterotic crosses obtained through biplot analysis showed similar heterotic effects for same crosses analyzed manually following standard formula, which confirmed the authenticity of the biplot in displaying the heterotic combinations. These heterotic crosses can be easily exploited through heterosis breeding, while, in segregating generation, the transgressive segregants can be exploited through recurrent breeding and biparental mating [27].

\section{Acknowledgments}

The authors are thankful to the Director for encouragement and facilities provided during the investigation. A. Rastogi and B. K. Mishra thank the Council of Scientific and Industrial Research, New Delhi, for giving senior research fellowship.

\section{References}

[1] A. B. Damania, "Near-eastern crop diversity and its global migration," in The Origin of Agriculture and Crop Domestication. Proceedings of the Harlan Symposium (ICARDA '97), A. B. Damania, J. Valkoun, G. Willcox, and C. O. Qualset, Eds., pp. 51-64, Aleppo, Syria, May 1997.

[2] S. Sood, N. R. Kalia, S. Bhateria, and S. Kumar, "Detection of genetic components of variation for some biometrical traits in Linum usitatissimum L. in sub-mountain Himalayan region," Euphytica, vol. 155, no. 1-2, pp. 107-115, 2007.

[3] M. Berti, S. Fischer, R. Wilckens, and F. Hevia, "Flaxseed response to N, P, and K fertilization in South Central Chile," Chilean Journal of Agricultural Research, vol. 69, no. 2, pp. 145153, 2009.

[4] M. Berti, S. Fischer, R. Wilckens, F. Hevia, and B. Johnson, "Adaptation and genotype $\times$ environment interaction of flaxseed (Linum usitatissimum L.) genotypes in south central Chile," Chilean Journal of Agricultural Research, vol. 70, no. 3, pp. 345-356, 2010.

[5] M. P. Chauhan, S. Singh, and A. K. Singh, "Post Harvest uses of Linseed," Journal of Human Ecology, vol. 28, pp. 217-219, 2009.

[6] M. Rai, H. Singh, and D. M. Hegde, Oilseeds and Oils research and Development Needs, Indian Society of Oilseeds Research, Directorate of Oilseeds Research, Hyderabad, India, 2002.

[7] F. López Anido, V. Cravero, P. Asprelli, T. Firpo, S. M. García, and E. Cointry, "Heterotic patterns in hybrids involving cultivar-groups of summer squash, Cucurbita pepo L," Euphytica, vol. 135, no. 3, pp. 355-360, 2004.

[8] A. R. Hallauer and J. B. Miranda, Quantitative Genetics in Maize Breeding, Iowa State University Press, Ames, Iowa, USA, 1981.

[9] G. F. Sprague and C. A. Tatum, "General vs specific combining ability single cross of corn," Journal of American Society of Agronomists, vol. 34, pp. 923-932, 1942.

[10] B. Griffing, "Concept of general and specific combining ability in relation to diallel crossing system," Australian Journal of Biological Sciences, vol. 9, pp. 463-493, 1956.

[11] R. K. Yadav and S. B. L. Srivastava, "Combining ability analysis over environments in linseed (Linum usitatissimum L.)," Crop Research, vol. 23, pp. 277-282, 2002.

[12] M. A. El-Komsan, A. M. El-Marakby, A. H. El-Sweify, and A. M. Tolba, "Combining ability analysis foe seed and straw yields and their components in a diallel cross of flax," Arab Universities Journal of Agriculture Sciences, vol. 11, no. 2, pp. 547-562, 2003. 
[13] A. Topal, C. Aydin, N. Akgün, and M. Babaoglu, "Diallel cross analysis in durum wheat (Triticum durum Desf.): identification of best parents for some kernel physical features," Field Crops Research, vol. 87, no. 1, pp. 1-12, 2004.

[14] S. K. Swarnakar, R. L. Srivastava, P. Singh, Y. P. Malik, and A. L. Yadav, "Studies on combinig ability and heterosis in linseed (Linum usitatissimum L.)," Farm Science Journal, vol. 14, no. 1, pp. 4-6, 2005.

[15] H. Goral, M. Jasienski, and T. Zając, "Combining abilities of several varieties of linseed with respect to yield components," Biuletyn Instytutu Hodowli Aklimatyzacji Roślin, vol. 240/241, pp. 237-242, 2006.

[16] L. Bertoia, C. López, and R. Burak, "Biplot analysis of forage combining ability in maize landraces," Crop Science, vol. 46, no. 3, pp. 1346-1353, 2006.

[17] W. Yan and L. A. Hunt, "Biplot analysis of diallel data," Crop Science, vol. 42, no. 1, pp. 21-30, 2002.

[18] N. F. Jensen, "A diallel selective mating system for cereal breeding," Crop Science, vol. 10, pp. 629-635, 1970.

[19] O. P. Verma and H. K. Srivastava, "Genetic component and combining ability analyses in relation to heterosis for yield and associated traits using three diverse rice-growing ecosystems," Field Crops Research, vol. 88, no. 2-3, pp. 91-102, 2004.

[20] C. Mahto and M. H. Rahman, "Heterosis for yield and yield components in linseed (Linum usitatissimum L.)," Journal of Research, vol. 13, no. 2, pp. 189-191, 2001.

[21] P. V. Satyanarayana, M. S. S. Reddy, I. Kumar, and J. Madhuri, "Combining ability studies on yield and yield components in rice," Oryza, vol. 37, pp. 22-25, 2000.

[22] M. Rahman, A. K. Patwary, and A. J. Miah, "Combining ability in rice," Indian Journal of Agriculture Sciences, vol. 15, pp. 543546, 1981.

[23] J. A. Patel and Y. K. Gup, "Genetic analysis in linseed under moisture stress condition," Madras Agricultural Journal, vol. 84, pp. 186-188, 1997.

[24] R. D. Ratnaparkhi, N. N. Kolte, and P. W. Khorgade, "Line $\mathrm{x}$ tester analysis for combining ability in linseed (Linum usitatissimum L.)," PKV Research Journal, vol. 22, no. 1, pp. 3-6, 1998.

[25] S. Bhateria, S. P. Sood, and A. Pathania, "Genetic analysis of quantitative traits across environments in linseed (Linum usitatissimum L.)," Euphytica, vol. 150, no. 1-2, pp. 185-194, 2006.

[26] V. Singh, M. P. Chauhan, K. Kumar, and R. B. Singh, “Triple test cross analysis for yield and yield contributing traits in linseed (Linum usitatissimum L.)," Research on Crops, vol. 7, no. 1, pp. 241-242, 2006.

[27] J. A. Patel, Y. K. Gupta, S. B. Patel, and J. N. Patel, "Combining ability analysis over environments in linseed," Madras Agricultural Journal, vol. 84, no. 4, pp. 188-191, 1997. 

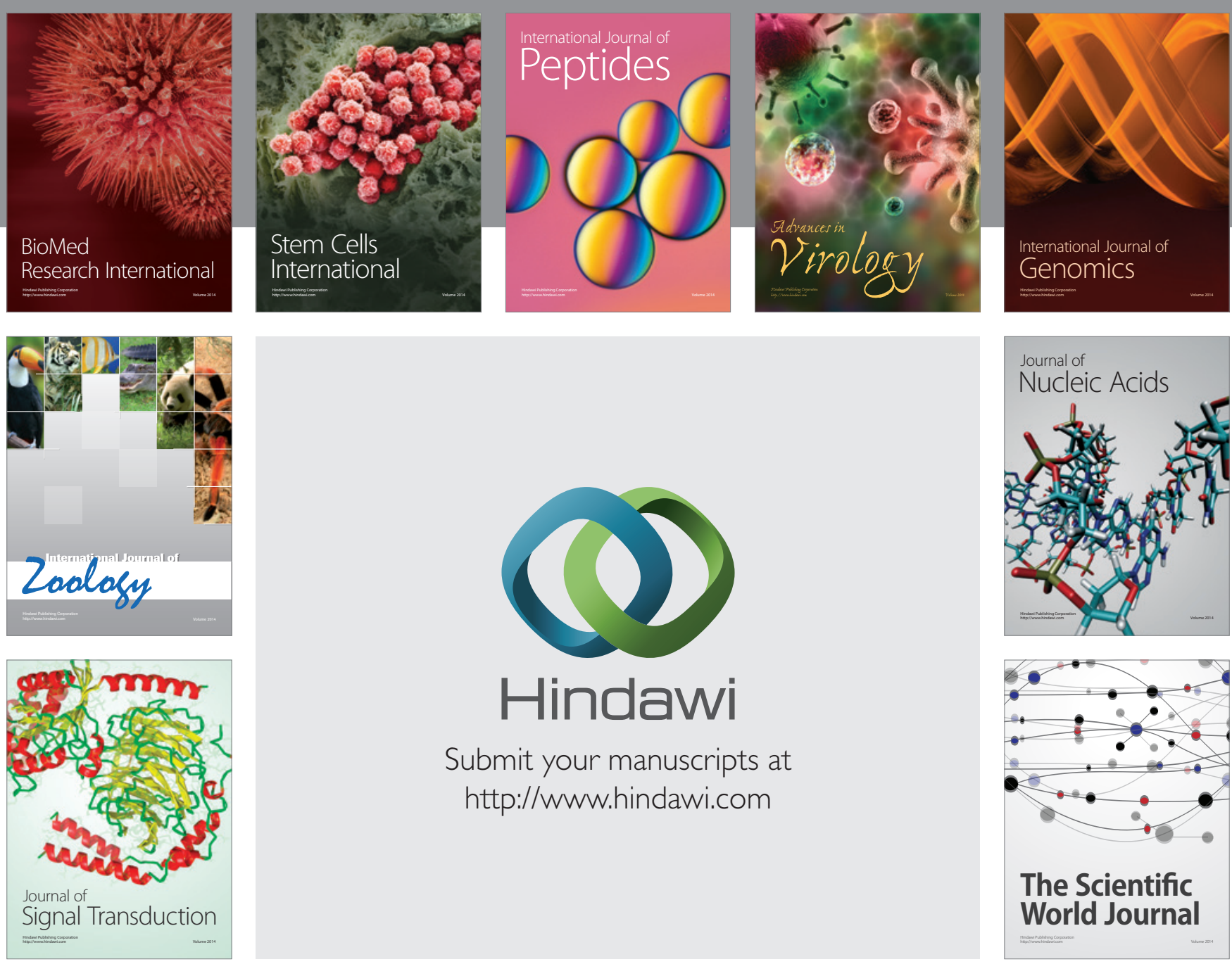

Submit your manuscripts at

http://www.hindawi.com
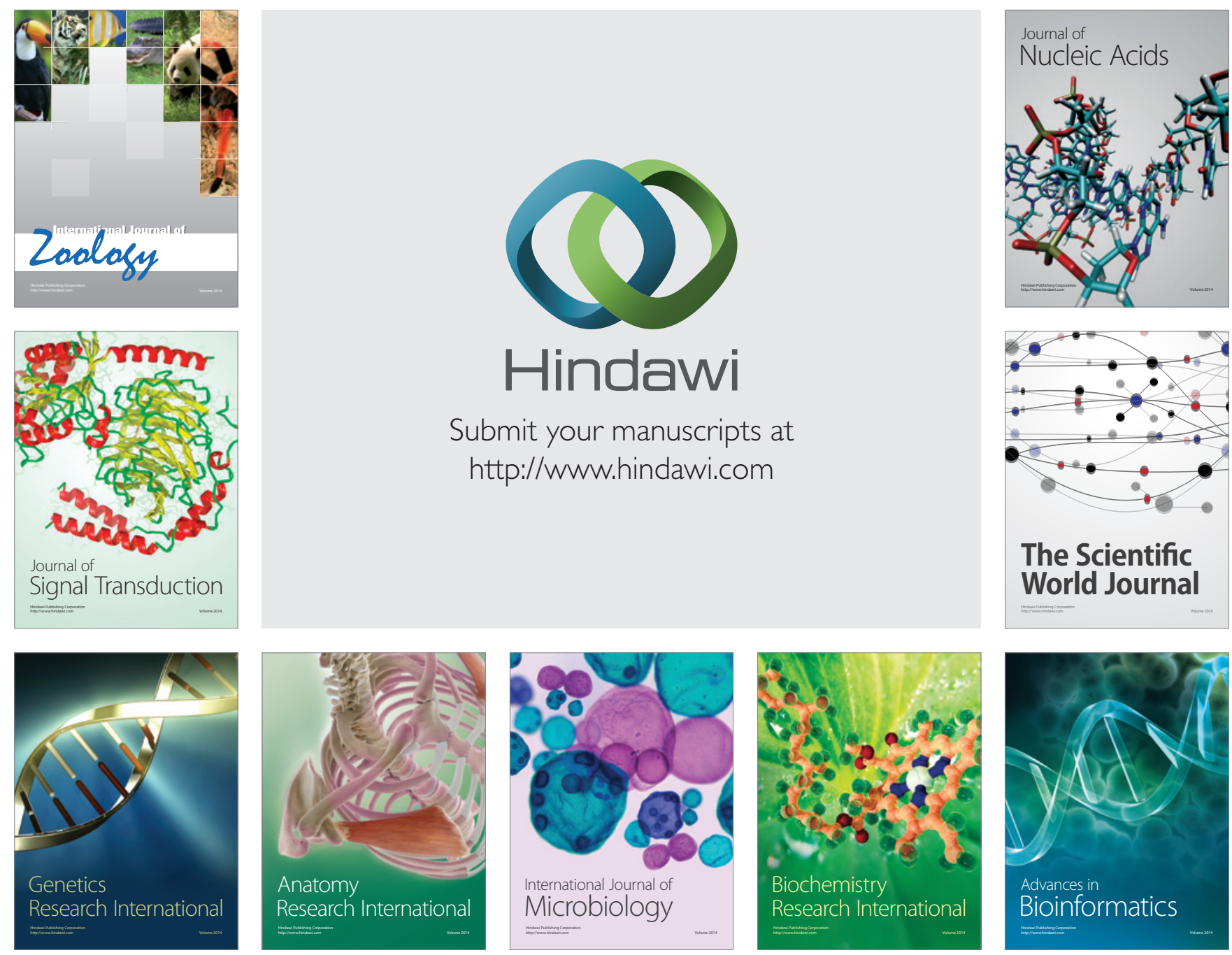

The Scientific World Journal
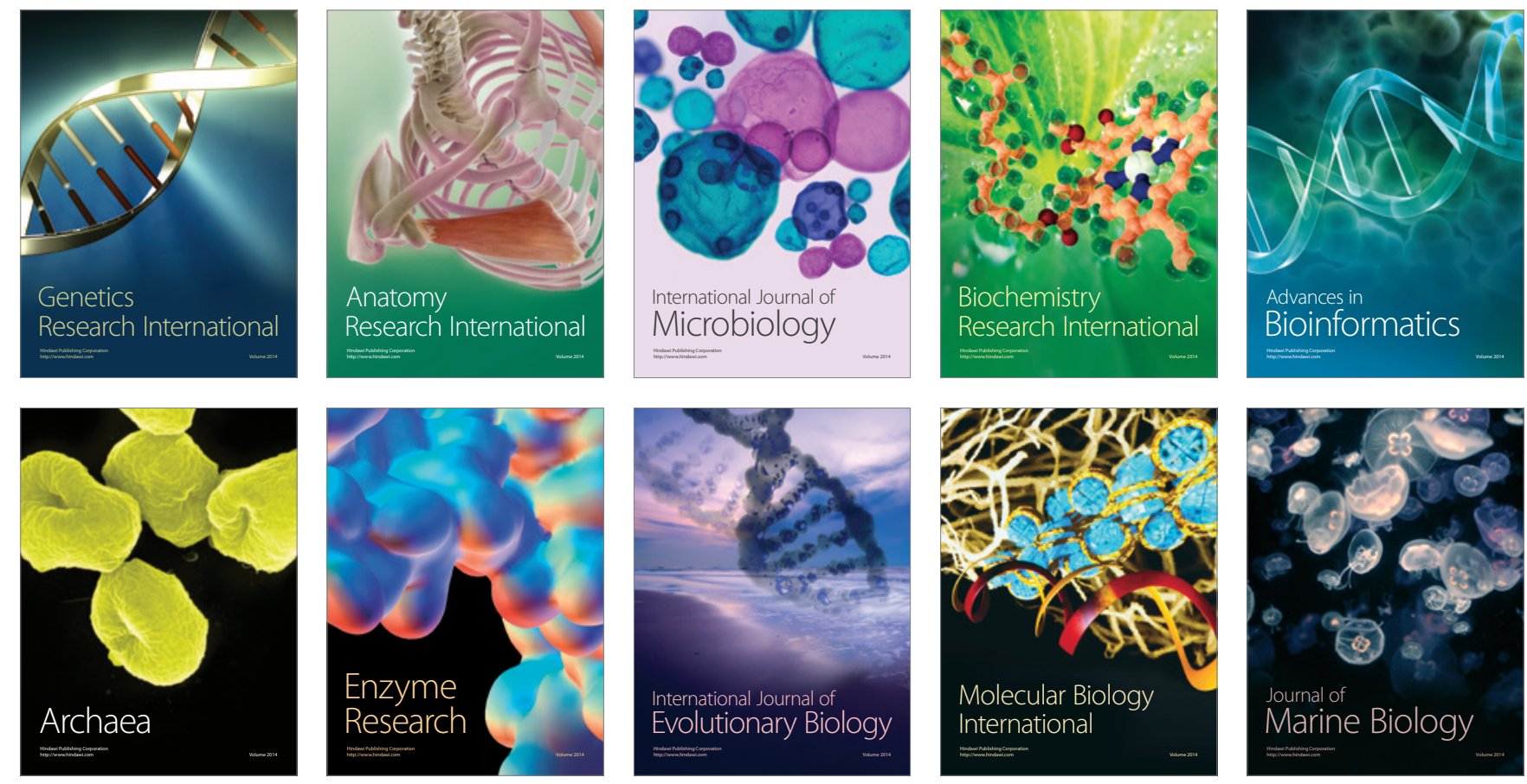